Indexaciones: Repositorio de Revistas UCR, DIALNET, Latindex, REDALYC Directorio y recolector de recursos digitales del Ministerio de Cultura de España, Directory of Open Access Journals. Diálogos Revista Electrónica de Historia ISSN 1409-469X. Número especial 2008. Dirección web: http://historia.fcs.ucr.ac.cr/dialogos.htm

\title{
Literatura, sociedad y discursividad crítica en el marco de la reflexión historiográfica centroamericana
}

\author{
Mijail Mondol López
}

Licenciado en Filología Española, estudiante de la Maestría en Literatura Latinoamericana y profesor de la Escuela de Ciencias de la Comunicación. Universidad de

Costa Rica.mijailmondol@hotmail.com Un antecedente importante de este trabajo lo constituye el Avance de Investigación presentado por Jorge Blanco Campos: Sobre la crítica centroamericana en la década crítica. (Avance 6. Centro de Investigación en Identidad y Cultural Latinoamericanas. 1995) 


\section{Introducción}

Actualmente, en el ámbito de los estudios literarios centroamericanos, la reflexión historiográfica ocupa una importante discursividad crítica en torno a las formas de categorización, periodización y análisis de las producciones literarias. Si bien es cierto, este panorama revela un campo metodológico activamente interdisciplinario en relación con las décadas anteriores, poco se ha dicho de la importancia que juega el discurso crítico en los procesos de significación cultural que realiza el sujeto histórico centroamericano a partir de la década de los noventa. ${ }^{1}$

Dimensionando la historiografía literaria como un género crítico particular, ésta nos permite visualizar distintos campos de refractación en las relaciones que se establecen entre el ámbito histórico y el discurso crítico-cultural, por lo que en este sentido partimos de la hipótesis de que la reflexión historiográfica trasciende su dimensión crítica al convocar un espacio de lectura/crisis del sujeto histórico centroamericano. Así pues, lejos de proponer una dimensión objetiva del discurso historiográfico en Centroamérica, nuestro ejercicio de lectura se fundamenta a partir de la siguiente interrogante: ¿Cómo se lee el sujeto histórico centroamericano en su historiografía?

Dada esta premisa, esta ponencia pretende rastrear un corpus crítico historiográfico, inscrito en el marco de la década de los noventa y principios del siglo XXI, con el objetivo de proponer una lectura en torno a las relaciones discursivas que se establecen entre el Sujeto Histórico, la Literatura y la praxis crítica-historiográfica centroamericana.

Una vez delimitado el corpus crítico-historiográfico en estudio, hemos de ensayar un acercamiento teórico entre la noción del sujeto histórico y el modelo comunicativo bajtiniano con el fin de especificar las dinámicas discursivas que se establecen entre el ámbito sociohistórico, la praxis literaria y el discurso crítico. De este modo, tomando como base las implicaciones 
teóricas que nos ofrece la dimensión dialógica del discurso, así como la importancia que ocupa el espacio del Tercero como instancia valorativa en la comunicación discursiva, nuestra propuesta de investigación dimensiona la praxis crítica como un importante ejercicio de mediación y conclusividad de sentido entre la noción del sujeto histórico y las producciones literarias centroamericanas.

\section{Tensiones globales y locales en los umbrales del siglo XXI}

“Julio se aseguró en la montura como lo hubiera hecho un caballero medieval en un torneo, antes de lanzarse sobre su contrincante. Clavó al potro las espuelas y sobre el camino férreo, a galope tendido fuese al encuentro del tren." (El Problema, Maximo Soto Hall, 1899.)

Posteriormente a los acontecimientos sociopolíticos que marcaron la década de los ochenta en Centroamérica, los procesos discursivos de democratización e integración centroamericana han ocupado, en las dos últimas décadas, un tema preponderante en la configuración de un espacio geopolítico regional.

Impulsado por los discursos oficiales de intervención internacional así como los procesos de modelización neoliberal de las economías locales, el concepto de región responde principalmente a la necesidad de articular una visión armónica y reconstruccionista frente a las contradicciones y desgarramientos sociopolíticos internos que se desprenden de los estados nacionales centroamericanos de posguerra. Así pues, la configuración de un espacio geopolítico regional se traduce en un ambivalente juego de tensiones entre el horizonte de las expectativas 
globales y el conflicto entre las particularidades locales e identitarias.

Por otra parte, la década de los noventa converge en Centroamérica con la intervención de un proceso económico global y tecnológico cuya incidencia entre los distintos países que conforman la región ha producido un trastrocamiento entre las relaciones Estado-nación y los imaginarios colectivos nacionales. En este sentido, y con base en el planteamiento que expone Maria de los Ángeles Palacios Robles en su ensayo: Estado-nación y nacionalismo: discursos de una práctica discontinua en la era de la información (2004), la crisis de la legitimidad del Estado-nación convoca nuevas estrategias discursivas de significación de la identidad y la otredad nacional:

"Hoy en día, las naciones y el nacionalismo asumen nuevas vías históricas como fuentes renovadas de identidad colectiva y de significado en la era de la información. Ante la fuerza homogenizadora de la globalización, que tiende a borrar las culturas locales y los particularismos identitarias, debitándolas, restándolas autonomía y auto dirección se produce un despertar de las identidades regionales y étnicas.” ${ }^{2}$

Asimismo, esta argumentación es apoyada por otros investigadores quienes caracterizan el impacto de la globalización como una fase económica capitalista cuya incidencia local repercute de manera interna en la funcionalidad simbólica del estado y la nación:

"Pero la globalización, como nueva etapa del capitalismo, experimenta también su impacto sobre las culturas y las sociedades del planeta. Quizás una de las producciones político-culturales que más golpes ha sentido en este proceso es la identidad nacional. Efectivamente, cuestionado el marco institucional en el que opera y tiene sentido -es decir el estado-, la nacionalidad pierde terreno y el conjunto de simbolismos que la animaban entran en deterioro. Al mismo tiempo, deja de jugar el papel fundamental en el desarrollo histórico que había tenido en el siglo XIX y en el siglo XX. Así el mundo de principios del siglo XXI se 2 María de los Ángeles Palacios Robles. Estado-nación y nacionalismo: discursos de una práctica discontinua en la era de la información. (Serie Cuadernos Historia de la Cultura. Editorial Universidad de Costa Rica. 2004), 30 
enfrenta a los problemas de las identidades locales y étnicas, cuando, a la vez, se tocan las trompetas de las identidades supranacionales." ${ }^{3}$

Finalmente, el proceso económico que involucra la globalización, tanto en su ámbito tecnológico como cultural, repercute actualmente en la configuración discursiva de nuevas estrategias de significación del tiempo y del espacio colectivo. Las nociones de territorialidad, identidad nacional y soberanía-ideologemas claves en la construcción del discurso Estado-nación decimonónico- ocupan en la actualidad un debate importante ante las demandas ideológicas que suponen un espacio y tiempo global. Tal como lo señala Álvaro Quesada en su texto: Breve Historia de la Literatura Costarricense (2000), la globalización económica y política altera, en el marco imaginario del Estado-nación, los criterios objetivos del espacio, el tiempo y la identidad nacional:

“Más allá del ámbito de los discursos político y económico, el concepto de "globalización” se encuentra también asociado al vertiginoso desarrollo de la tecnología, la informática y la comunicación en los decenios finales del siglo. Las nuevas tecnologías y la informática transformaron la producción y el consumo de bienes y servicios, hicieron surgir una "realidad virtual o un "ciberespacio" ubicuo, liberado de las fronteras geográficas o nacionales y las constricciones destiempo y el espacio objetivos, y contribuyeron, junto con la globalización económica y política o el impacto de las nuevas culturas de masas, a modificar los criterios establecidos de imaginar o simbolizar la realidad y a trastocar una de las formaciones tradicionales - ligada al Estado, la nación o la cultura vernácula- de construirse como sujeto, “ ${ }^{4}$

3 David Díaz Arias. Las rutas históricas de la globalización. (Serie Cuadernos Historia de la Cultural. Editorial Universidad de Costa Rica.2007), 20

$4 \quad$ Álvaro Quesada Soto. Breve historia de la literatura costarricense (San José. Editorial Universidad de Costa Rica. 2000), 45 
Dado este marco explicativo entre los procesos de globalización y las demandas discursivas que se infiltran en la configuración de un espacio geopolítico regional, hemos de afirmar que si en primera instancia las tensiones globales y locales se revelan en las estrategias político económicas, el ámbito cultural - y particularmente el de la crítica - no es ajeno a las transformaciones y búsquedas de sentido que efectúa el Sujeto histórico centroamericano por explicar (se) su producción simbólica en el marco de la contemporaneidad. La emergencia de una producción ensayística en torno a las particularidades culturales y literarias que integran la región, así como los intentos del discurso crítico por articular una visión conjunta y multidisciplinaria revelan una importante enunciación crítica cuya praxis y circulación de escritura se encuentra íntimamente relacionada con las tensiones geopolíticas y socioculturales que manifiesta la región centroamericana a partir de la década de los noventa y principios de la década del siglo XXI.

\section{Umbrales y fronteras del discurso crítico historiográfico centroamericano}

Paralelamente con el surgimiento de nuevas configuraciones textuales y discursivas de la novela centroamericana contemporánea, la emergencia de un discurso crítico-historiográfico no se hace esperar en la escena académica e institucional de los estudios literarios.

En este sentido, es importante destacar que la llamada producción novelística posnoventa converge simultáneamente en Centroamérica con el surgimiento de una actividad académica mucho más especializada en comparación con las décadas anteriores. La existencia de distintos centros de estudio e investigación, así como los constantes esfuerzos interdisciplinarios por 
articular una visión cultural e histórica centroamericana no son ajenos a las perspectivas críticohistoriográficas que buscan elaborar una interpretación conjunta de las formaciones literarias y las formaciones socioculturales centroamericanas.

Tal y como se señala en innumerables artículos y producciones ensayísticas, la década de los noventa convoca un espacio de reflexión en torno a las limitaciones y posibilidades de significación de una lectura regional y multidisciplinaria. Esta pertinencia académica no solamente plantea la necesidad de nuevos acercamientos metodológicos frente a las distintas producciones culturales centroamericanas, sino que también revela por demás un proceso de desarticulación de los modelos historiográficos nacionales así como su eventual articulación con una lectura historiográfica centroamericana. ${ }^{5}$

Finalmente, la década de los noventa representa también para Centroamérica una etapa de transición metacrítica respecto al análisis de las producciones culturales y literarias de la región, específicamente en el ámbito de la crítica y la historiografía literaria. Por lo que en este sentido, cabe destacar que es precisamente en esta década donde se revela una transición significativa entre las producciones crítico-historiográficas de carácter parcial y la aproximación de una crítica historiográfica de índole regional y comparativista. ${ }^{6}$

5 A propósito, de esta perspectiva historiográfica regional, cabe reseñar el proyecto de investigación: Hacia una Historia de la Literatura Centroamericana, coordinado por el Centro de Investigación en Identidad y Cultura Latinoamericanas (CIICLA) de la Universidad de Costa Rica.

6 Tal y como lo menciona Alexandra Ortiz, en su artículo: Historias de la literatura nacional en Centroamérica (2005), podemos afirmar que la formación de una conciencia metacrítica historiográfica regional se formula a partir de las reflexiones de Ligia Bolaños: "Discurso histórico e historiografía literaria: ¿Una alternativa en la construcción de un discurso explicativo de las producciones culturales en América Central? (1988), Magda Zavala y Seidy Araya; La historiografia literaria en América Central (1957-1987) (1995) y Werner Mackenbach: Problemas de una historiografia literaria en Nicaragua (1997). Asimismo, es imprescindible mencionar la importancia que ocupan las propuestas críticas culturales realizadas por Rafael Cuevas Molina Identidad y Cultura en Centroamérica (2006), Traspatio florecido - tendencias de la dinámica cultural en Centroamérica (1979-1990) (1993) y Arturo Arias: Gestas Ceremoniales (1998) 
Dada la amplia diversidad teórico metodológica que caracterizan las prácticas críticodiscursivas desarrolladas en la década de los noventa y principios del siglo XXI, nuestra propuesta de investigación se limita, en esta fase, a proponer un panorama descriptivo de las principales formas de aproximación del discurso crítico-historiográfico. Para este fin, hemos propuesto cuatro categorías de estudio con el propósito de establecer distintos niveles de discursividad crítica a partir de la muestra de algunas producciones crítico-ensayísticas.

\section{Crítica historiográfica}

En primer lugar, corresponde conceptualizar la crítica historiográfica como el conjunto de perspectivas que tienden a evaluar las implicaciones teórico-metodológicas de las distintas historias nacionales y centroamericanas. En este sentido, la crítica historiográfica, tal y como la concebimos, constituye una práctica analítica del discurso histórico-literario.

Un ejemplo paradigmático de esta perspectiva de estudio se manifiesta en el texto de Magda Zavala y Seydi Araya: La historiografía literaria en América Central (1995). En este documento, las autoras esbozan un panorama descriptivo en torno a las principales tendencias historiográficas que caracterizan las historias literarias nacionales producidas en el periodo de 1957-1987. Basadas en el planteamiento teórico de Beatriz González Losada y Ana Pizarro, las 7 Específicamente, las historias literarias nacionales revisadas por estas investigadoras son: Historia de la Literatura Costarricense (1957) Abelardo Bonilla, Desarrollo Literario de El Salvador (1958) Juan Felipe Toruño, Panorama de la Literatura nicaragüense (1966) Jorge 
investigadoras señalan, a manera de conclusión, la vigencia de un programa ideológico liberal en la construcción discursiva de las historias nacionales consultadas:

“En conclusión las historias literarias en Centroamérica de 1950 al presente, vistas sus características, poco difieren de lo logrado por los maestros liberales del siglo XIX. El impacto de las tendencias inmanentes se ha visto sólo en el abandono de los cortes temporales de la historia política. Por lo demás, la historiografía literaria sigue siendo intensamente biografista.",

Siguiendo esta misma perspectiva de análisis, el artículo de Alexandra Ortiz: Historias de la literatura nacional en Centroamérica. Tendencias, continuidades y perspectivas. (2005) plantea un panorama crítico-descriptivo en relación con las distintas historias nacionales centroamericanas producidas, fundamentalmente en la década de los ochenta. ${ }^{9}$ En términos generales, este texto abarca el análisis de algunas categorías histórico-literarias tales como: la literatura como categoría clasificatoria e instrumento de poder, el concepto de literatura nacional y la construcción del canon literario.

De similar importancia, cabe destacar el conjunto de artículos especializados que abordan las implicaciones ideológicas de las antologías y revistas literarias en la construcción de referentes culturales de índole nacional. Así, pues, este tipo de textos son evaluados, al igual que la

Eduardo Arellano, La Literatura Panameña. Origen y Proceso (1970), Rodrigo Miró, Historia de la Literatura Guatemalteca (1981-1982-1986) Albizúrez y Barrios, Literatura Hondureña y su proceso generacional (1987, José Francisco Martínez.

8 Magda Zavala y Seidy Araya. La historiografía literaria en América Central (19571987) (Heredia. Editorial Fundación UNA 1995), 200

9 Algunas de las referencias histórico literarias que menciona esta investigadora son: $\mathrm{Pa}$ norama de la literatura salvadoreña. Del periodo precolombino a 1980. Gallego Valdés, Luis, 1981. Historia de la literatura guatemalteca. Albizúrrez Palma, Franciso/Barrios y Barrios, Catalina. 1986. La literatura panameña (origen y proceso). $7^{\mathrm{a}}$ ed. 1987. Literatura hondureña y su proceso generacional. 1987. José Franciso Martínez. 
producción de las historias literarias, como formas de legitimación de un discurso institucional de las producciones crítico-literarias. ${ }^{10}$

Tal es el caso del artículo de Leonel Delgado Aburto: Las antologías y el problema del texto emblemático (2000), en donde se señala la función que desempeñan las antologías poéticas en la constitución de la ideología nacional, el canon y sus posibles contradiscursos:

“Este artículo pretende ilustrar de manera muy general ciertos funcionamientos de las antologías de poesía nicaragüense en su labor canónica, y de frente a tres factores que me parecen fundamentales para iniciar una crítica que contribuya a una necesaria actualización de sus concepciones y lecturas. Primero, cabrá analizar la relación de las antologías (valga decir el relato poético) y la constitución del nacionalismo y la idea de nacionalidad. En segundo lugar habrá que intentar un estudio comparativo con otras naciones centroamericanas que no padezcan de manera tan acentuada el síndrome de “ombligo del mundo de la poesía”. Y en tercer lugar, y es quizá el punto más importante, habrá que interrogarse por las microhistorias de los grupos marginalizados por el canon (valga decir en este caso las antologías) y cómo se afianzan sus estrategias de recanonizaciones o contradiscursos.” 11

Tomados los ejemplos anteriores como muestras de la crítica historiográfica, es importante mencionar que los principales enfoques analíticos de esta perspectiva se inscriben en el marco de una lectura de los procesos de formación del estado nacional y su imbricación en el desarrollo de la institucionalidad literaria. ${ }^{12}$

10 En este mismo sentido, no podemos dejar de mencionar la investigación realizada por Flora Ovares: Literatura de kiosco. Revista literarias de Costa Rica. (1994), así como el artículo de Werner Mackenbach.: ¿El centro vacío de la periferia? Acerca de dos Historias de la Literatura Latinoamericana, editadas en Alemania por Michael Rössner y Hans-Otto Dill.

11 Leonel Delgado Aburto. "Las antologías y el problema del texto emblemático", Istmo. Revista virtual de estudios literarios y culturales, 1 (enero-junio.2001) http://collaborations. denison.edu/istmo/n1/artículos/productores.html (Fecha de acceso 3 de febrero 2008)

12 Un antecedente significativo en relación con esta perspectiva lo constituye el ensayo de Ramón Luis Acevedo: La novela centroamericana. Desde el Pool-Vuh hasta los umbrales de la 


\section{Historiografía crítica}

En segundo lugar, y a diferencia de la crítica historiográfica cuyo objeto de estudio lo constituyen las distintas prácticas histórico-literarias, la historiografía crítica se dimensiona principalmente como un campo de reflexión en torno a las categorías y propuestas generadas por el discurso historiográfico. De esta manera, su funcionamiento crítico radica en la problematización y proposición de nuevos enfoques y categorías de estudio que permitan una mayor articulación teórico metodológica entre el ámbito historiográfico y la formalización de un discurso histórico literario.

Tomando en cuenta el periodo historiográfico que ocupa esta investigación, diversas han sido las propuestas y problematizaciones historiográficas que se orientan a la formalización tentativa de una historia literaria centroamericana.

En este sentido, corresponde nuevamente mencionar la propuesta historiográfica que desarrolla Magda Zavala y Seydi Araya en su texto: La historiografia literaria en América Central (1957-1987) 1995, como un documento de referencia en torno a una visión integradora e interdisciplinaria de una historia literaria centroamericana. Dicha propuesta se articula con base en los siguientes aspectos:

1. La relatividad cultural del concepto de literatura

2. La diversidad literaria

3. El lugar y función de lo literario

4. El conflicto entre la ideología nacionalista y las concepciones eurocéntricas

5. La perspectiva comparatista

novela actual (1982) así como el artículo de Ligia Bolaños: "Discurso histórico e historiografía literaria: ¿Una alternativa en la construcción de un discurso explicativo de las producciones culturales en América Central?" (1988) 
6. Conceptualización regional de los estudios literarios centroamericanos

7. Reevaluación conceptual de la disciplina histórica

8. La periodización literaria.

Asimismo, el artículo de Franz Galich: "Prolegómenos para una Historia de las Literaturas Centroamericanas" ensaya, grosso modo, las posibilidades de articulación de una historia literaria centroamericana. Entre sus principales argumentaciones se señalan las siguientes:

\section{a) “Conceptualizar Centroamérica.}

En este aspecto, Galich elabora un balance general de algunas destacadas producciones historiográficas tales como: Historia de la poesía en América Central (1975, Menéndez Pelayo), Historia de la literatura hispanoamericana (1985, Giuseppe Bellini), Historia de la literatura hispanoamericana (1962, Anderson Imbert,) Diccionario de escritores centroamericanos (1997, Jorge Eduardo Arellano), La novela centroamericana (1982, Ramón Luis Acevedo), Poesía centroamericana postmodernista y de vanguardia (1988, Francisco Albizúrez Palma) con el objetivo de demostrar la variabilidad geopolítica y cultural que subyace en la conceptualización de la región centroamericana.

Así pues, la indeterminación geográfica, política, y cultural, que subyace en la definición de los distintos países que conforman el istmo centroamericano, se presenta para este autor como un primer problema metodológico en la conformación de una historia literaria centroamericana. b) Conceptualización de lo literario centroamericano.

En segundo lugar, este crítico problematiza la conceptualización de la literatura centroamericana a partir de los criterios de selección (materiales a historiar) y revisión dinámica 
del canon y la teoría de los géneros.

\section{c) Periodización literaria}

Como tercer aspecto metodológico, el cuestionamiento de la periodización, valga decir la delimitación temporal de los textos literarios, constituye un tema fundamental dentro de la formulación de una práctica histórica literaria. Al respecto de esta problemática, Galich menciona las siguientes posibilidades y expectativas de articulación:

- Vigencia de un desarrollo asimétrico de tiempo, espacio y de las producciones literarias centroamericanas y del continente latinoamericano en general:

- Inclusión de la literatura escrita por mujeres, literatura contemporánea y producción subalterna.

- Inclusión de la producción oral

\section{d) El problema de los productores y la recepción. ¿Literatura culta o popular?}

En un cuarto aspecto, Galich, apunta a la dicotomía entre literatura de elite y literatura popular como un problema constitutivo en los mecanismos de producción y recepción de los textos literarios Este aspecto lo conduce, a plantear una historia literaria capaz de articular todos los discursos que hasta la fecha han sido subalternizados.

\section{e) Perspectiva multidisciplinaria.}

Finalmente, en su último prolegómeno este autor evalúa las posibilidades de escribir una historia literaria con una concepción centroamericanista, afirmando así una actitud 
multidisciplinaria en relación con los estudios literarios y culturales.

Por otra parte, y tal como lo apuntábamos anteriormente, la historiografía crítica se agrupa en diversos artículos y producciones ensayísticas cuyo objetivo de investigación se traduce en la constitución de nuevas categorías de periodización y enfoques historiográficos. En este sentido, corresponde al artículo de Alexandra Ortiz Wallner: Narrativas centroamericanas de posguerra: problemas en la constitución de una categoría de periodización literaria $(2004)^{13}$ reflexionar acerca de las posibilidades de significación que ofrece el término de posguerra dentro de los estudios historiográficos literarios y culturales.

Tal y como lo explica esta misma investigadora, la referencia a este criterio abarca no solamente una categoría de periodización literaria, sino que también abarca el conjunto de perspectivas críticas culturales, políticas e históricas:

"Interesa aquí particularmente, articular las diversas perspectivas que algunos de estos estudios ofrecen acerca de la época de la posguerra reciente en Centroamérica, en el sentido que, si se toma como un periodo, la posguerra no es una noción puramente literaria, sino que se relaciona también con la historia de las ideas, de las culturas y de las sociedades implicadas." ${ }^{14}$

Finalmente, esta investigadora evalúa el criterio de posguerra como un criterio abierto e interdisciplinario dentro de las diversas perspectivas historiográficas. De este modo, la utilidad

13 En este artículo, Ortiz problematiza el criterio de periodización literaria a partir de dos momentos particulares en la dinámica crítica de la historia literaria. De esta manera, corresponde en un primer momento al artículo de Ramón Luis Acevedo: La novela centroamericana. Desde el Pool-Vuh hasta los umbrales de la novela actual, (1982) en conjunto con el texto de Magda Zavala y Seídy Araya: La historiografía literaria en América Central (1957-1987) (1995), plantear una discursividad crítica en torno a las perspectivas historiográficas nacionales producidas a partir de la segunda mitad del siglo XX. Posteriormente, un segundo corpus de estudio se manifiesta en la época de transición democrática posterior a los conflictos bélicos centroamericanos ocurridos durante la década de los ochenta y cuya producción critica es analizada por Ortiz bajo la categoría de posguerra.

14 Alexandra Ortiz Wallner. "Narrativas centroamericanas de posguerra: problemas de la constitución de una categoría de periodización literaria” Revista Iberoamericana. 19 (2005) 144 
operativa de este concepto, valga decir su uso instrumental como categoría de periodización literaria, constituye para Ortiz un importante núcleo de referencia en los procesos literarios y culturales que caracterizan la región durante la década de los noventa y principios del siglo XXI.

“El uso instrumental del término posguerra como categoría de periodización literaria es importante en la medida en que permite cartografiar una determinada producción textual dentro de la continuidad de los procesos literarios de la región. Se trata de una categoría abierta que debe ser interrogada constantemente: por una lado plantea la cuestión de los alcances y limitaciones de las posibilidades de representación de las voces plurales que están emergiendo en toda la región, y por otro lado, ha ido conformando un discurso crítico que se preocupa por trazar territorios con el fin de encontrar nuevos enfoques que articulen una de las dimensiones de los procesos que viven las literaturas centroamericanas." 15

De similar importancia, la historiográfica crítica aborda el tema del género literario como una categoría de análisis dentro de la constitución de las historias y estudios crítico literarios. Tal es el caso del conjunto de artículos y producciones ensayísticas que plantean una revisión conceptual del género histórico y testimonial producidos durante la década de los noventa y principios del siglo XXI.

Una muestra significativa de esta perspectiva historiográfica se manifiesta en el artículo de Werner Mackenbach: "La nueva novela histórica en Nicaragua y Centroamérica" (2001) ${ }^{16}$, donde plantea una revisión conceptual de la novela histórica así como el análisis de las distintas aproximaciones y resignificaciones ideológicas que realiza la narrativa centroamericana 15 Ibid, 146

16 Véase Werner Mackenbach "La nueva novela histórica en Nicaragua y Centroamérica" Istmo. Revista de estudios literarios y culturales. 1 (enero - junio 2001) 
contemporánea en torno a este género y sus prácticas de escritura. En segundo lugar, corresponde al artículo de Valeria Grinberg: La novela histórica de finales del siglo XXY las nuevas corrientes historiográficas $(2001)^{17}$, reflexionar acerca de la relaciones de ruptura- continuidad entre las distintas prácticas de escritura de este género y las tendencias historiográficas contemporáneas.

Así mismo, cabe señalar la profundización de estudios respecto al género testimonial y autobiográfico, por lo que a manera de ejemplo corresponde ubicar el texto de Francisco Rodríguez Cascante: Autobiografía y dialogismo (2004) como un documento de referencia en torno al análisis del género autobiográfico y su dimensión dialógica en la constitución del sujeto histórico.

Finalmente, la valoración del ensayo como categoría de estudio amplia el horizonte de la historiografía crítica al proponer la inclusión de prácticas crítico-discursivas dentro de las perspectivas de los estudios literarios y culturales. Tal es la propuesta de investigación que proporcionan los investigadores Werner Mackenbach y Alexandra Ortiz en los siguientes artículos: "Ensayar una historia cultural de Centroamérica” (2006) y “ELl ensayo en Centroamérica: ¿(sub)género literario y/o contribución al estudio de las culturas y literaturas centroamericanas?" (2006)

Como se puede apreciar en este panorama general, la historiografía crítica circunscribe sus focos de análisis en torno a ciertas categorías historiográficas tales como la periodización, el canon literario y el género testimonial, histórico, autobiográfico y ensayístico con el fin de plantear propuestas de análisis de las producciones literarias e histórico-literarias.

17 Véase Valeria Grinberg. "La novela histórica de finales del siglo XX y las nuevas corrientes historiográficas" Istmo. Revista de estudios literarios y culturales. 1 (enero-junio 2001) 


\section{Discurso crítico: perspectivas literarias y culturales}

Consecuentemente con la crítica historiográfica y la historiografía crítica anteriormente comentadas, el discurso crítico presupone el análisis de las producciones literarias en tanto dimensiona el fenómeno textual como una praxis de sentido. No obstante, como es lógico de suponer, esta perspectiva no solamente abarca una amplia heterogeneidad temática, sino que también presupone una gran variabilidad teórica y metodológica, asimismo cabe destacar la naturaleza híbrida de esta práctica discursiva cuyas propuestas de análisis oscilan entre los estudios socio-culturales y literarios. Dada la complejidad de este campo de estudios, nos limitamos a describir sus articulaciones más significativas con base en una selección de artículos y publicaciones ensayísticas. ${ }^{18}$

Un primer campo de articulación se manifiesta en las propuestas críticas que tienden a inscribir la producción narrativa centroamericana dentro de un marco socio-discursivo de referencia. Así, pues, desde este posicionamiento teórico, la producción textual centroamericana es valorada a partir de los discursos y modelos de representación que evidencian (¿reflejan?) una fundamentación principalmente sociológica y extraliteraria. Por lo que en este sentido, la problematización de los estudios críticos se restringe a analizar las formaciones discursivas literarias como campos de representación y mediación ideológica de ciertas formaciones sociopolíticas. De acuerdo con lo anterior, el espacio urbano, el tema de la violencia y la marginalidad social, constituyen algunos ejes temáticos de esta perspectiva de estudio. Veamos, pues, algunas de sus manifestaciones críticas más representativas:

Como primer documento de referencia, el artículo de Beatriz Cortez: “La construcción

18 Específicamente, en esta categoría de estudio nos referiremos a los estudios crítico literarios que corresponden a la novela centroamericana. 
de la identidad como fuente de violencia y su representación en la literatura centroamericana de posguerra" (2002), ensaya, a grandes rasgos, una de las temáticas más sobresalientes de la novelística de la década de los noventa. La mediación discursiva de la violencia y la marginalidad, como un marco explicativo de algunas de las representaciones estético-literarias ${ }^{19}$ estudiadas, es vista por esta investigadora a la luz de las tensiones que se generan entre los modelos oficiales de identidad nacional y los sujetos o sectores marginales que emergen en los nuevos proyectos literarios:

"Mi propósito para este ensayo es hacer una lectura del proceso de construcción de la identidad como un proyecto generador de exclusiones, y, por lo tanto, de violencia, ilustrando este proceso a partir de la representación literaria de esta violencia en la ficción de posguerra.” 20

De similar importancia, la Tesis de Maestría elaborada por Alexandra Ortiz: Transiciones democráticas/ transiciones literarias. Sobre la novela centroamericana de posguerra (2001) señala que los procesos discursivos de democratización, inscritos en la década de los noventa, activan, en la producción novelística centroamericana, la emergencia de nuevos sectores sociales emergentes. De allí, pues, que el concepto de transición constituya un elemento clave en la explicación de los nuevos espacios discursivos que explora la producción literaria de

19 Las producciones literarias evaluadas por Beatriz Cortéz se concentran en las siguientes referencias textuales: "Carretera sin buey", "Fauna de alcantarilla" y "Vaca" (Cuentos) de la escritora salvadoreña Claudia Hernández. "Prohibido vivir" del escritor salvadoreño Salvador Canjura, "Anita, la cazadora de insectos" del escritor hondureño Roberto Castillo. Trece, novela del escritor Rafael Menjivar, Ningún lugar sagrado Rodrigo Rey Sosa y Baile con serpientes (1996) del escritor Horacio Castellanos Moya.

20 Beatriz Cortez. "La construcción de la identidad como fuente de violencia y su representación en la literatura centroamericana de posguerra" Ponencia presentada en el X Congreso Internacional de Literatura Centroamericana, 22-24 de abril 2002. Instituto Ibero-Americano, Berlín (no publicada) 
posguerra.

Sustentada por algunas perspectivas filosóficas postmodernistas, la propuesta crítica de Beatriz Cortez elaborada en su ensayo: Estética del cinismo: la ficción centroamericana de posguerra (2000), recoge una serie de caracterizaciones en torno a la construcción de la subjetividad y su vinculación con el espacio urbano.

Tal y como lo menciona la propia investigadora, la inclusión del espacio urbano dentro de las producciones ficcionales centroamericanas permite la exploración subjetiva e intimista de los personajes. De esta forma, la ciudad se transforma en un mecanismo de negociación de la identidad nacional y de la exploración subjetiva:

“[...] al análisis de la ficción contemporánea y de la forma en que ésta explora la intimidad y la negociación de la subjetividad en el espacio urbano [...] Este trabajo propone una interpretación de una selección de textos de los autores Salvador Canjura, Claudia Hernández y Rafael Menjívar, Horacio Castellanos y Rodrigo Rey Sosa. Sus textos se analizan a partir de una serie de propuestas filosóficas respecto a la construcción de la subjetividad, la exploración de las pasiones y la voluntad del individuo, así como teorizaciones respecto a la fragmentación de la identidad que caracterizan a la posmodernidad. ${ }^{21}$

Por otra parte, los estudios de identidad nacional y cultural centroamericana, promovidos durante los inicios de la década de los noventa y cuyos aportes teóricos denotan un carácter activamente interdisciplinario en las distintas aproximaciones críticas literarias, se traducen específicamente en el estudio de los nuevos espacios colectivos y subjetivos que configura la novela centroamericana así como su consecuente repercusión frente a la crisis de los modelos oficiales de la identidad nacional.

21 Beatriz Cortes. "Estética del cinismo: la ficción centroamericana de posguerra", ponencia presentada en el V Congreso Centroamericano de Historia, 18-21 de julio. 2000), 1-2 no publicada. 
En este sentido, cabe mencionar el artículo el artículo de Jeffrey Browitt: Literatura nacional y el ocaso del discurso de la nación-estado en Centroamérica (2000), en donde explica la emergencia de una conciencia de ruptura/desmitificación de los proyectos de nación-estado a través de la producción novelística de Manlio Argueta y Sergio Ramírez. De este modo, este investigador alude a la producción literaria de estos dos autores centroamericanos como un campo de re/significación de los discursos de identidad nacional.

\section{Metahistoriografía}

Finalmente, la reflexión historiográfica centroamericana, inscrita en la década de los noventas y principios del siglo XXI, convoca una lectura metahistoriográfica tiende a evaluar desde una dimensión crítico-epistemológica las distintas aproximaciones conceptuales del discurso historiográfico. A diferencia de la crítica historiográfica, la historiográfia crítica o la crítica textual, este posicionamiento de estudio se traduce en un ámbito de reflexión del discurso y del saber historiográfico.

Como principal referente de esta perspectiva, corresponde mencionar el artículo de Werner Mackenbach: "Después de los pos-ismos: ¿desde que categorías pensamos las literaturas centroamericanas contemporáneas?" (2004). En este texto se plantea un panorama crítico en torno a las conceptualizaciones que rige el discurso historiográfico contemporáneo. Según señala este investigador, la proliferación de diversas categorías que subyacen en las aproximaciones crítico historiográficas contemporáneas afirman una etapa transitoria en los estudios criticoliterarios. No obstante, y basados en el planteamiento crítico que señala Mackenbach, nuestra propuesta de lectura tiende a explicar la diversidad de categorizaciones historiográficas, como un proceso de resistencia y replanteamiento del sujeto histórico centroamericano. 
Tal y como se deduce de las categorías anteriormente señaladas (crítica historiográfica, historiografía crítica, discurso crítico y metahistoriografía) es claro determinar la formación de un programa crítico-discursivo durante la década de los noventa y principios del siglo XXI. Así pues, dado el panorama heteroglósico que manifiestan las distintas aproximaciones de estudio, podemos repensar el discurso crítico a manera de una novela estilísticamente polífónica. No obstante, esta figuración cobra una mayor especificidad de análisis si introducimos la dimensión dialógica como un eje epistémico en las relaciones que se establecen entre el sujeto histórico y las distintas producciones de sentido.

\section{Sujeto histórico/ Sujeto crítico}

\footnotetext{
“ De allí que el intelectual centroamericano contemporáneo mime, hable con la lengua enrollada, con una lengua picantemente paródica, irónica, esperando el momento en que pueda colarse entre las grietas del discurso hegemónico antes de que el poder de éste último lo nombre, congelando en el acto" (Arturo Arias. Gestos Ceremoniales)
}

Tomando como base las implicaciones teóricas que nos ofrece el modelo comunicativo bajtiniano y particularmente la función que ocupa el espacio del Tercero como respuesta ética en la dinámica dialógica y comprensiva del discurso, nuestra propuesta de investigación articula la noción del sujeto histórico y el sujeto crítico como una instancia valorativa de la praxis social y sus producciones de sentido. Dado este preámbulo, consideramos pertinente esbozar algunos conceptos teóricos del modelo sociodiscursivo de Mijail Bajtin con el fin de establecer una 
relación entre el sujeto histórico y el discurso crítico.

\section{Aproximación teórica del modelo diálogico bajtiniano.}

“[...] la palabra siempre quiere se oída (...) siempre busca comprensión como respuesta.” (Mijail Bajtin)

Cuatro son los conceptos que, a nuestro parecer, hilvanan una aproximación teórica del modelo comunicativo bajtiniano. En primer lugar, y basados en la elaboración teórica que realiza Bajtin en torno a la naturaleza diálogica del enunciado, el primer aspecto a destacar en su teoría corresponde a la dinámica de respuesta que ocupan los enunciados en la comunicación discursiva. Tal y como lo explica este teórico: “[...] todo enunciado debe ser analizado, desde un principio, como respuesta a los enunciados anteriores de una esfera dada $[\ldots]^{22}$. Así pues, este principio de respuesta, se erige como el principal fundamento diálogico del modelo comunicativo bajtiniano.

Asimismo, es importante destacar que la noción de respuesta que elabora este teórico, difiere radicalmente de una interpretación funcionalista e inclusive dialéctica del lenguaje. Muy por el contrario, Bajtin es claro en especificar que el ámbito de la respuesta/responsibidad determina una múltiple posición valorativa, por lo que en este sentido, la respuesta puede activar una valoración de consenso, polémica, crítica u obediencia, según el ámbito de la esfera discursiva. ${ }^{23}$ De allí, que en un sentido amplio, la respuesta es aquí comprendida como un acto 22 Mijail Bajtin, Estética de la creación verbal.(Buenos Aires, Argentina, Editorial Siglo XXI 2002), 281

23 Véase al respecto la siguiente cita textual, donde Bajtin explica las variabilidad valorativa de la respuesta, así como su importancia radical en la estructuración y límites del enunciado: "En efecto, el oyente, al percibir y comprender el significado (lingüístico) del discurso, simultáneamente toma con respecto a éste una activa postura de respuesta: está o no está de acuerdo con el discurso (total o parcialmente), lo complementa, lo aplica, se prepara para una acción, etc. y la postura de respuesta del oyente está en formación a lo largo de todo el proceso de audición y comprensión desde el principio, a veces, a partir de las primeras palabras del hablante. Toda comprensión de un discurso vivo, de un enunciado viviente, tiene un carácter de respuesta (a pesar de que el grado de participación puede ser muy variado) toda comprensión está 
de sentido y valoración del enunciado.

La activación dialógica de la respuesta, se constituye, por tanto, como la energía social de la comunicación discursiva, convirtiendo al destinatario del enunciado en un oyente activo. De esta manera, como lo explica el propio Bajtin, la instancia destinataria del enunciado, se convierte a su vez en un hablante. Esta alternancia revela, pues, que la dinámica de respuesta actúa como un mecanismo de posicionamiento de los sujetos discursivos. En este sentido, léase, por tanto, la siguiente cita textual donde se especifica la importancia que ocupa el ámbito de la respuesta en los sujetos discursivos y por ende en la constitución dialógica de los enunciados:

“En la realidad el problema resulta ser mucho más complejo. Todo enunciado concreto viene a ser un eslabón en la cadena de la comunicación discursiva en una esfera determinada. Las fronteras mismas del enunciado se fijan por el cambio de los sujetos discursivos. Los enunciados no son indiferentes uno a otro ni son autosuficientes, sino que "saben" uno del otro y se reflejan mutuamente. Estos reflejos recíprocos son los que determinan el carácter del enunciado. Cada enunciado está lleno de ecos y reflejos de otros enunciados con los cuales se relaciona por la comunidad de la esfera de la comunicación discursiva."24

Una vez comprendido el principio de respuesta como la principal energía de la comunicación discursiva, hemos de articular un segundo concepto en el modelo comunicativo bajtiniano y cuya explicación es clave para entender las implicaciones en un modelo sociohistórico de la comunicación discursiva: la comprensión como respuesta.

Relacionado con la dinámica de respuesta anteriormente comentada, el concepto de

preñada de respuesta y de una u otra manera la genera: el oyente se convierte en hablante. Una comprensión pasiva del discurso percibido es tan sólo un momento abstracto de la comprensión total y activa que implica una respuesta, y se actualiza en la consiguiente respuesta en voz alta. Claro, no siempre tiene lugar una respuesta inmediata en voz alta; la comprensión activa del oyente puede traducirse en una acción inmediata puede asimismo queda por un tiempo como una comprensión silenciosa (comprensión retardada) ( Ibid, 257)

Ibid.,265 
comprensión surge a manera de una demanda futura y valorativa del enunciado. Lo que en otras palabras significaría que la comprensión, según Bajtin, se halla estructurada en el horizonte valorativo (no explicativo) que demanda la morfogénesis de toda construcción discursiva. De este modo, las relaciones dialógicas que se establecen entre los enunciados no solamente deben ser vistas como respuestas anteriores de otros eslabones discursivos, sino también como la demanda futura e histórica de un horizonte valorativo previsto y organizado en la génesis misma del discurso. Leamos, pues, la siguiente cita textual donde Bajtin explica en detalle las implicaciones de la respuesta como comprensión del enunciado:

“Pero un enunciado no sólo está relacionado con los eslabones anteriores, sino también con los eslabones posteriores de la comunicación discursiva. Cuando el enunciado está en la etapa de su creación por el hablante, estos últimos, por supuesto, aún no existen. Pero el enunciado se construye desde el principio tomando en cuenta las posibles reacciones de respuesta para las cuales se construye el enunciado. El papel de los otros, como ya sabemos es sumamente importante. Ya hemos dicho que estos otros, para los cuales mi pensamiento se vuelve tal por primera vez (y por lo mismo) no son oyentes pasivos sino los activos participantes de la comunicación discursiva. El hablante espera desde el principio su contestación y su comprensión activa. Todo el enunciado se construye en vista de la respuesta." ${ }^{25}$

Ubicada la categoría de comprensión como una demanda valorativa del enunciado, el modelo comunicativo bajtiniano evidencia, la instancia de un tercero. Efectivamente, la fundamentación teórica del modelo dialógico bajtiniano, entendido como un modelo tripartito de la comunicación discursiva, enfatiza la función del tercero (oyente) ${ }^{26}$ como un núcleo activo 25 Ibid., 285

26 De singular importancia, el concepto del oyente cobra para Mijail Bajtin una connotación radicalmente contraria de la postura lingüística: "En la lingüística hasta ahora persisten tales ficciones como el "oyente" y "el que comprende" (los compañeros del "hablante"), la "corriente discursiva única", etc. Estas ficciones dan un concepto absolutamente distorsionado del proceso complejo, multilateral y activo de la comunicación discursiva. (...) No se 
en la comprensión dialógica del discurso. Entendido este Tercero como acto de respuesta en la comprensión del discurso, es importante esclarecer que dicha categoría se encuentra ligada, simultáneamente, a la valoración del sentido del enunciado. De allí pues, que valoración y comprensión constituyan para Bajtin, una unidad ética y epistemológica:

“La categoría de comprensión abarca la lengua y el enunciado, lo cual involucra la necesidad de la respuesta del enunciatario, y con ella una valoración del sentido, puesto que el enunciado es visto como una totalidad de sentido: mi comprensión de las voces de la palabra. En la vinculación del comprender y el valorar adquiere función el acto primero, que deviene en responsabilidad; no se puede separar compresión y valoración: son simultáneas y constituyen un acto total. El que comprende se acerca a la obra con una visión del mundo propia y ya formada, con su punto de vista, desde sus posiciones (...) En el acto de la comprensión se lleva cabo una lucha, cuyo resultado es un cambio y un enriquecimiento mutuo." ${ }^{27}$

Inscrito en los fundamentos de una poética social, el espacio del Tercero, tal y como lo hemos definido en el apartado anterior, supone un núcleo trans-histórico en los procesos de recepción y valorización del sentido discursivo. Tal y como lo explica Iris Zavala, en su texto ya clásico: La Posmodernidad y Mijail Bajtin: "el paso decisivo en el modelo comunicativo de Bajitn está en el papel del interlocutor activo y que responde (nunca un receptor pasivo) y en que el “tercero" es fundamental en el intercambio cultural. (El subrayado es nuestro).

Sujeto de la comprensión y de la valoración del enunciado, la instancia del Tercero supone en Bajtin un más allá de la interacción discursiva inmediata. No obstante, es importante destacar puede decir que tales esquemas sean falsos y no correspondan a determinados momentos de la realidad, pero, cuando tales momentos se presentan como la totalidad real de la comunicación discursiva, se convierten en una ficción científica." (Bajtin,

$27 \quad$ Ibid., 318 
que este horizonte valorativo que prefija toda comunicación discursiva no debe interpretarse como una mediación metafísica u externa del acontecimiento comunicativo, sino más bien, como hemos destacado con anterioridad, una demanda histórica de respuesta organizada internamente en la praxis dialógica del discurso. En este sentido, véase la siguiente cita textual donde el propio Bajtin especifica la relación entre la comprensión como respuesta y el lugar que ocupa el tercero en la comunicación discursiva:

"Los enunciados no pueden ser comprendidos desde afuera. La comprensión misma forma parte, en tanto que momento dialógico, del sistema dialógico y de alguna manera cambia su sentido total. El que comprende se vuelve inevitablemente el tercero del diálogo (desde luego, no en sentido literal, aritmético, porque además del tercero puede presentarse un número infinito de participantes de un diálogo comprendido), pero la posición dialógica de este tercero es una posición muy específica. Todo enunciado siempre tiene un destinatario (de diferentes tipos, de diversos grados de cercanía, de concretización, de reconocimiento, etc) cuya comprensión de respuesta es buscada por el autor de la obra y es anticipada por él mismo. El destinatario es el segundo del diálogo (otra vez, no en un sentido aritmético). Pero además del destinatario (del segundo) el autor del enunciado supone la existencia de un destinatario superior (el tercero) cuya comprensión de respuesta absolutamente justa se prevé o bien en un espacio metafísico, o bien en un tiempo históricamente lejano" 28

Finalmente, y acorde con la concepción bajtiniana del Tercero, la dimensión del sujeto histórico ocupa un concepto fundamental para comprender la operatividad que tiene este modelo dentro de la dinámica discursiva/responsiva de los sujetos sociales. Planteamiento, que sin lugar a dudas, constituye la verdadera trascendencia teórica de Mijail Bajtin.

Efectivamente, tal y como lo propone Francisco Rodríguez en su libro: Autobiografia y

$28 \quad$ Ibid 
dialogismo (2004), podemos establecer una conexión teórica entre la instancia del Tercero y la dimensión del sujeto histórico:

“El tercero, el que tiene la responsabilidad de comprender es, de acuerdo con nuestra interpretación, en primera instancia el sujeto histórico visto no como individualidad, sino como la prospección de la sociedad en el tiempo, con las proyecciones de valores sociales que cohesionan a ese sujeto. [...] El tercero es la sociedad que se piensa así misma (pero no debe entenderse esta como una abstracción, sino como las relaciones sociales concretas realizadas entre sujetos humanos en ese espacio de praxis llamado sociedad) y debe comprenderse para conocerse, para asegurar su socialidad, su supervivencia, por eso la comunicación es un drama en que participan tres, el segundo no basta para cohesionar proyectos sociales colectivos, son necesarios los valores y la comprensión de estos valores, ante los cuales es necesario un compromiso ético de entendimiento y solidaridad." $\left.{ }^{29}: 214-215\right)$

Así pues, cabe destacar la función valorativa y comprensiva que subyace en el sujeto histórico y cuya reflexión ética de sí mismo le permite asegurar su praxis social o lo que es lo mismo su cohesión como sujeto. De este modo, el horizonte valorativo, entendido éste como el marco dialógico de la praxis y de las proyecciones sociales en los que se inscribe el sujeto histórico ocupa, al igual que la instancia del Tercero, una comprensión como respuesta, es decir un ejercicio de valoración. Dicho en otros términos, el sujeto histórico, no es sino el lugar de la demanda y del deseo de la praxis social; del gran Otro.

Elaborados estos cuatro conceptos de la comunicación discursiva (dinámica de respuesta, la comprensión como respuesta, el espacio del tercero y el sujeto histórico), podemos aproximarnos a una lectura respecto a la dinámica comunicativa que se establece entre el discurso crítico, la

29 Francisco Rodríguez Cascante. Autobiografía y dialogismo. ( Editorial Universidad de Costa Rica. 2004), 214-215 
praxis literaria y el ámbito sociohistórico.

Como bien señalábamos en la explicación del modelo comunicativo bajtiniano, la activación de la respuesta del enunciado constituye el principio dialógico de la comunicación discursiva. De esta manera, y siguiendo en detalle la concepción teórica de los géneros secundarios propuesta por Bajtin, es importante subrayar que las formaciones discursivas, literarias o críticas, obedecen a distintos sistemas de enunciación, y que, no obstante, ambas formaciones comparten una misma naturaleza dialógica dado su inscripción social e histórica. ${ }^{30}$

De acuerdo con las implicaciones teóricas anteriores, nuestro estudio parte del presupuesto de que la discursividad crítica, ubicada en la década de los noventa y principios del siglo XXI, se construye a partir de una dinámica de respuesta del discurso estético-literario con el fin de determinar una comprensión valorativa.

Partiendo de este principio dialógico que se establece entre la palabra crítica y la palabra literaria, la noción de comprensión, elaborada en el marco comunicativo bajtiniano, ocupa una particularidad cualitativa de todo discurso crítico. Tal y como hemos señalado, Bajtin establece que todo enunciado se prefija ante las expectativas que demanda un horizonte valorativo. Así pues, en el ámbito del discurso historiográfico, ésta se articula en un código valorativo el cual intenta objetivar/inscribir un posicionamiento histórico-cultural de las producciones significantes.

Finalmente, es precisamente en la demanda valorativa que prefigura el discurso crítico, donde se establece la instancia de un tercero - el sujeto histórico-.y cuya comprensión, en tanto oyente participativo, permite asegurar (se) un lugar central en las relaciones que se establecen

30 Efectivamente, en el capitulo correspondiente al problema de los géneros discursivos, Bajtin sostiene que pese a la diversidad, de géneros discursivos es posible determinar una naturaleza común del enunciado. Según este teórico, esta heterogeneidad es tan amplia y tan compleja, que hasta el momento no ha existido un planteamiento metodológico que logre articular una misma naturaleza. Esto explica el hecho de que los estudios se limiten a estudiar ciertos tipos de géneros (géneros literarios) sin atenerse a estudiar su especificidad común con otros discursos. 
entre el discurso critico, el discurso literario y la praxis social, permitiendo así el resurgimiento de nuevas significaciones culturales.

\section{Del paradigma nacional a la incertidumbre crítica: ¿Conclusiones?}

"El sujeto está llamado a renacer para saber si quiere lo que desea" Jacques Lacan

Inscrito en las contradicciones de la modernidad oligárquico - liberal, el sujeto histórico centroamericano surge en la formación de los estados nacionales. Dada esta coyuntura histórica, el paradigma nacional se concibe, durante gran parte del siglo XX, como la tendencia crítica dominante del sujeto histórico y sus producciones simbólicas.

Una de las razones principales que explica la predominancia de esta tendencia se constata precisamente en el contexto crítico de la década de noventa y principios del siglo XXI, en cuyo discurso historiográfico se propone la descentralización de los paradigmas historiográficos nacionales así como la evaluación crítica del discurso de identidad y cultural nacional.

Por otra parte, no podemos omitir, en el actual contexto centroamericano, la manifestación de una incertidumbre crítica en torno a las relaciones que se establecen entre el sujeto histórico y su producción literaria. La emergencia de nuevas categorizaciones y planteamientos metodológicos por parte del discurso crítico historiográfico revela así un nuevo posicionamiento crítico del sujeto histórico centroamericano, razón por la cual la crisis del paradigma y del referente del estado-nación, como espacio ético y colectivo de la praxis social, trastoca indudablemente el discurso crítico centroamericano hacia nuevas fronteras y experimentaciones epistemológicas.

Dimensionado el Sujeto Histórico como una instancia valorativa-comprensiva en 
torno a las relaciones que se establecen entre el discurso crítico y la praxis histórico- social, la reflexión historiográfica de la década de los años noventa y principios del siglo XXI convoca nuevas estrategias de significación del panorama histórico-literario y de las prácticas críticoliterarias. La emergencia de una discurso centroamericanista de integración cultural, así como la descentralización de las perspectivas historiográficas de índole nacional, constituyen, en este sentido, dos importantes tendencias críticas del sujeto histórico centroamericano y sus prácticas significantes.

Asimismo, diversas han sido las explicaciones que intentan justificar una aproximación historiográfica de carácter regional; por un lado, algunos investigadores insisten en señalar un cambio de paradigma dentro de los estudios literarios, mientras que otras posiciones convienen estudiar las producciones críticas y culturales a partir de los nuevos fenómenos socioculturales que se desarrollaron en Centroamérica una vez finalizada su etapa de entreguerras. No obstante, cabe destacar que dicha disyuntiva es comúnmente justificada bajo los términos de un cambio de paradigma de los estudios literarios, negando la interpretación histórica del sujeto crítico como una instancia de lectura de la praxis social y sus producciones de sentido. 